\title{
Nocturnal manifestations of Parkinson's disease and atypical Parkinsonism
}

\author{
Heinz Reichmann • Roongroj Bhidayasiri
}

Received: 21 February 2014/ Accepted: 25 February 2014/Published online: 22 March 2014

(C) Springer-Verlag Wien 2014

In this Supplement of the Journal of Neural Transmission, we address an important feature of Parkinson's syndrome, i.e. nocturnal problems. We feel very honoured that so many eminent experts in this field have contributed to a supplement which should be of interest to everyone who deals with Parkinson's disease (PD).

It is accepted by neuroscientists that PD is a progressive disease with an accumulation of $\alpha$-synuclein (Spillantini et al. 1997). Since these accumulations are also found in the mesencephalon where sleep regulation is located, it follows that impairment of sleep is a natural consequence of this progressive disease (Braak et al. 2003). Even James Parkinson addressed sleep problems in his essay on the shaking palsy when he writes "....as the malady proceeds, the sleep becomes much disturbed..." (Parkinson 1817).

REM sleep behaviour disorder (RBD) is associated with hyposmia, constipation and depression as among the most frequent and important pre-motor symptoms in PD (Bhidayasiri and Reichmann 2013; Reichmann 2010). Patients with RBD lack physiological atonia during REM sleep and frequently scream and move violently, often injuring their

\section{H. Reichmann}

Klinik und Poliklinik fur Neurologie, Universitatsklinikum Carl Gustav Carus, Dresden, Germany

R. Bhidayasiri $(\bowtie)$

Department of Medicine, Faculty of Medicine, Chulalongkorn Center of Excellence on Parkinson's Disease and Related Disorders, Chulalongkorn University and King Chulalongkorn Memorial Hospital, Thai Red Cross Society, Bangkok 10330, Thailand

e-mail: rbh1@ucla.edu

R. Bhidayasiri

Department of Neurology, Geffen School of Medicine at UCLA, Los Angeles 90095, USA sleeping partners. More than $60 \%$ of these patients will later develop a second neurodegenerative disorder, very often PD or atypical parkinsonism (Claassen et al. 2010). But there are many more nocturnal disturbances in patients with PD such as nocturia, pollakisuria, problems falling asleep, problems staying asleep, restless legs syndrome, pain during nighttime, early morning akinesia and many more (Grandas and Iranzo 2004). Patients rate nighttime problems rather high when they are asked what impairs their quality of life the most (Barone et al. 2009). Thus, it is obvious that we need scales to quantify these features. Fortunately, such scales have been developed which give a good estimate of sleep problems in PD (Hogl et al. 2010). For others we can use the Parkinson's disease sleep scale (PDSS) or the scales for outcomes in PD sleep (SCOPA-S) (Chaudhuri et al. 2002; Marinus et al. 2003). Of all nonmotor symptoms in $\mathrm{PD}$, sleep problems belong to the most serious ones since they do not only impair quality of sleep and rest but also impair motor performance in the early morning and give rise to fatigue and somnolence during daytime (Comella 2006). Both nighttime and daytime problems also impair the quality of life of the patients' caregivers since they do not find enough rest to take care of the patients during the daytime (Martinez-Martin et al. 2007).

Thus, treatment of nocturnal problems in PD is extremely important. Most PD specialists use a long-acting dopamine replacement therapy to address a dopaminergic trough during the nighttime (Ray Chaudhuri et al. 2012; Trenkwalder et al. 2011). It is helpful to use extendedrelease preparations of levodopa since there would not be any interference with food at nighttime (Chouza et al. 1990). Long-acting dopamine agonists are extremely helpful to overcome nighttime problems and to increase the possibility of a good start of the next day. In addition, the 
use of MAO-B inhibitors or COMT inhibitors may be a good option (Rascol et al. 2011; Reichmann and Emre 2012). RBD can be addressed by the use of clonazepam and melatonin (Aurora et al. 2010; Kunz and Mahlberg 2010).

Finally, it should also be noted that patients with a socalled atypical parkinsonism suffer from nighttime problems and also need help to address these features. RBD is found in multiple system atrophy (MSA), dementia with Lewy body (DLB), progressive supranuclear palsy (PSP) and corticobasal syndrome (CBS) (Arnulf et al. 2005; Boeve et al. 2001, 2013; Cooper and Josephs 2009). MSA is also associated very often with sleep apnea and periodic limb movements. DLB is often associated with extensive daytime sleepiness (Arnulf 2005; Hirayama et al. 2003).

In conclusion, addressing nighttime problems and solving them by adequate treatment are of major importance for our PD patients and using this supplement will certainly help in achieving this goal.

Conflict of interest The authors have no conflict of interest.

\section{References}

Arnulf I (2005) Excessive daytime sleepiness in parkinsonism. Sleep Med Rev 9(3):185-200

Arnulf I, Merino-Andreu M, Bloch F, Konofal E, Vidailhet M, Cochen V et al (2005) REM sleep behavior disorder and REM sleep without atonia in patients with progressive supranuclear palsy. Sleep 28(3):349-354

Aurora RN, Zak RS, Maganti RK, Auerbach SH, Casey KR, Chowdhuri $S$ et al (2010) Best practice guide for the treatment of REM sleep behavior disorder (RBD). J Clin Sleep Med 6(1):85-95

Barone P, Antonini A, Colosimo C, Marconi R, Morgante L, Avarello TP et al (2009) The PRIAMO study: a multicenter assessment of nonmotor symptoms and their impact on quality of life in Parkinson's disease. Mov Disord 24(11):1641-1649

Bhidayasiri R, Reichmann H (2013) Different diagnostic criteria for Parkinson disease: what are the pitfalls? J Neural Transm 120(4): 619-625

Boeve BF, Silber MH, Ferman TJ, Lucas JA, Parisi JE (2001) Association of REM sleep behavior disorder and neurodegenerative disease may reflect an underlying synucleinopathy. Mov Disord 16(4):622-630

Boeve BF, Silber MH, Ferman TJ, Lin SC, Benarroch EE, Schmeichel AM et al (2013) Clinicopathologic correlations in 172 cases of rapid eye movement sleep behavior disorder with or without a coexisting neurologic disorder. Sleep Med 14(8):754-762

Braak H, Del Tredici K, Rub U, de Vos RA, Jansen Steur EN, Braak E (2003) Staging of brain pathology related to sporadic Parkinson's disease. Neurobiol Aging 24(2):197-211

Chaudhuri KR, Pal S, DiMarco A, Whately-Smith C, Bridgman K, Mathew R et al (2002) The Parkinson's disease sleep scale: a new instrument for assessing sleep and nocturnal disability in Parkinson's disease. J Neurol Neurosurg Psychiatry 73(6): 629-635

Chouza C, Aljanati R, Caamano JL, De Medina O, Scaramelli A, Buzo R et al (1990) Long-term treatment with Madopar HBS in parkinsonians with fluctuations. Adv Neurol 53:519-526

Claassen DO, Josephs KA, Ahlskog JE, Silber MH, Tippmann-Peikert M, Boeve BF (2010) REM sleep behavior disorder preceding other aspects of synucleinopathies by up to half a century. Neurology 75(6):494-499

Comella CL (2006) Sleep disturbances and excessive daytime sleepiness in Parkinson disease: an overview. J Neural Transm Suppl 70:349-355

Cooper AD, Josephs KA (2009) Photophobia, visual hallucinations, and REM sleep behavior disorder in progressive supranuclear palsy and corticobasal degeneration: a prospective study. Parkinsonism Relat Disord 15(1):59-61

Grandas F, Iranzo A (2004) Nocturnal problems occurring in Parkinson's disease. Neurology 63(8 Suppl 3):S8-S11

Hirayama M, Fukatsu H, Watanabe H, Koike Y, Noda A, Ito H et al (2003) Sequential constriction of upper airway and vocal cords in sleep apnoea of multiple system atrophy: low field magnetic resonance fluoroscopic study. J Neurol Neurosurg Psychiatry 74(5):642-645

Hogl B, Arnulf I, Comella C, Ferreira J, Iranzo A, Tilley B et al (2010) Scales to assess sleep impairment in Parkinson's disease: critique and recommendations. Mov Disord 25(16):2704-2716

Kunz D, Mahlberg R (2010) A two-part, double-blind, placebocontrolled trial of exogenous melatonin in REM sleep behaviour disorder. J Sleep Res 19(4):591-596

Marinus J, Visser M, van Hilten JJ, Lammers GJ, Stiggelbout AM (2003) Assessment of sleep and sleepiness in Parkinson disease. Sleep 26(8):1049-1054

Martinez-Martin P, Forjaz MJ, Frades-Payo B, Rusinol AB, Fernandez-Garcia JM, Benito-Leon J et al (2007) Caregiver burden in Parkinson's disease. Mov Disord 22(7):924-931 quiz 1060

Parkinson J (1817) Essay on the shaking palsy. Sheerwood, Neely and Jones, London

Rascol O, Fitzer-Attas CJ, Hauser R, Jankovic J, Lang A, Langston JW et al (2011) A double-blind, delayed-start trial of rasagiline in Parkinson's disease (the ADAGIO study): prespecified and post hoc analyses of the need for additional therapies, changes in UPDRS scores, and non-motor outcomes. Lancet Neurol 10(5): 415-423

Ray Chaudhuri K, Martinez-Martin P, Rolfe KA, Cooper J, Rockett $\mathrm{CB}$, Giorgi $\mathrm{L}$ et al (2012) Improvements in nocturnal symptoms with ropinirole prolonged release in patients with advanced Parkinson's disease. Eur J Neurol 19(1):105-113

Reichmann H (2010) Clinical criteria for the diagnosis of Parkinson's disease. Neurodegener Dis 7(5):284-290

Reichmann H, Emre M (2012) Optimizing levodopa therapy to treat wearing-off symptoms in Parkinson's disease: focus on levodopa/carbidopa/entacapone. Expert Rev Neurother 12(2):119131

Spillantini MG, Schmidt ML, Lee VM, Trojanowski JQ, Jakes R, Goedert M (1997) Alpha-synuclein in Lewy bodies. Nature 388(6645):839-840

Trenkwalder C, Kies B, Rudzinska M, Fine J, Nikl J, Honczarenko K et al (2011) Rotigotine effects on early morning motor function and sleep in Parkinson's disease: a double-blind, randomized, placebo-controlled study (RECOVER). Mov Disord 26(1):90-99 